\title{
La propuesta de proyecto de nación de Gamio en Forjando patria (pro nacionalismo) y la crítica del sistema jurídico-político mexicano de principios del siglo $X X$
}

\author{
Guillermo Castillo Ramírez
}

En el contexto histórico de la Revolución Mexicana de 1910 y en el marco de las ideas de Manuel Gamio sobre los indígenas, este trabajo estudia la caracterización y el análisis del proyecto de nación esbozado exclusivamente en Forjando patria (pro nacionalismo) ([1916] 1992). Tras la descripción de las condiciones sociales e históricas de esta obra, se analiza la crítica de Gamio al sistema político-legal del México de inicios del siglo XX. Después se indagan las características con las que Gamio definió una nación consolidada. Posteriormente, se delinea el proceso de cambio sociocultural a fin de que México tuviera una nacionalidad integrada y definida. Por último, se describe el papel que la disciplina antropológica estaba destinada a desempeñar en las dinámicas de convergencia propuestas por Gamio.

PALABRAS CLAVE: Gamio, historia de la antropología mexicana, nación, grupos étnicos, Estado

\section{Gamio's Proposal of Nation Project in Forjando patria (pro nacionalismo) and the Critic of the Mexican Juridical-Political System in the Beginning of the $20^{\text {th }}$ Century}

In the historical context of Mexico of the Revolution of 1910 and inside the frame of Gamio's ideas about indigenous people, this work deals the characterization and analysis of the nation project drawn mainly in Forjando patria (pro nacionalismo) ([1916] 1992).After the description of the historical and social conditions of the work, this article analyzes Gamio critic to the legal and politic system of Mexico during the very beginning of the $20^{\text {th }}$ Century. Then, this text researches the characteristics that Gamio considered to define a consolidated nation. After this, the article delineates the sociocultural change process to achieve an integrated and defined nationality. Finally, the paper describes the fundamental role that anthropology was meant to perform within the convergence dynamics proposed by Gamio.

KEYWORDS: Gamio, history of mexican anthropology, nation, ethnic groups, State

Guillermo Castillo Ramírez: Facultad de Estudios Superiores Acatlán, Universidad Nacional Autónoma de México,

Naucalpan, Estado de México, México

saudadegris@yahoo.com

Desacatos, núm. 43, septiembre-diciembre 2013, pp. 111-126

Recepción: 21 de abril de 2012 / Aceptación: 23 de enero de 2013 


\section{EL CONTEXTO HISTÓRICO Y PROPÓSITOS DE FORJANDO PATRIA (PRO NACIONALISMO)}

$F$ Torjando patria (pro nacionalismo) se publicó en 1916, cuando Gamio era funcionario de la Inspección General de Monumentos Arqueológicos (González, 1987: 39). Fue el mismo año de los preparativos del Congreso Constituyente que desembocó en la Constitución de 1917, en el periodo institucionalista carrancista de la Revolución Mexicana (Garciadiego, 2011: 249; Garciadiego y Kuntz, 2010: 562-563). En esta obra, Gamio trazó un proyecto de nación con el ánimo de contribuir a los debates sobre la reconstrucción del país. El propósito del libro, según señaló el autor en el "Prefacio", fue:

remover impulsos nacionalistas e ideas gestadoras de Patria. [...] Considéresele como una deslumbrada faceta que débilmente refleja aspectos nacionales y como sincero portavoz de necesidades y anhelos apenas expresados pero hondamente sentidos por la población (Gamio, [1916] 1992: 3). ${ }^{1}$

En Forjando patria (pro nacionalismo), Gamio buscaba una finalidad política y práctica que consideraba impostergable: la incorporación activa a la vida social y política del país de un gran sector de la población de inicios del siglo xx: los grupos indígenas. Esta preocupación, eje del proyecto nacional de Forjando patria (pro nacionalismo), se mantuvo presente durante el quehacer profesional y académico de este antropólogo y cobró especial relevancia en las dos últimas décadas de su vida, mientras dirigió el Instituto Interamericano Indigenista (III), de 1942 a 1960. ${ }^{2}$

\footnotetext{
${ }^{1}$ Al final de Forjando patria (pro nacionalismo), Gamio reitera su intención de respaldar el nacionalismo revolucionario: "[Considérese Forjando patria (pro nacionalismo)] como humilde contribución al resurgimiento nacional que se prepara" (Gamio, [1916] 1992: 183).

${ }^{2}$ En 1916, previo a la publicación de Forjando patria (pro nacionalismo), en la ponencia presentada en el II Congreso Científico
}

Forjando patria (pro nacionalismo) también fue de gran relevancia para la vida académica de Gamio, debido a que en esta obra trazó un amplio programa de investigación de carácter integral para las disciplinas antropológicas, que posteriormente llevaría a cabo en la Dirección de Antropología (Mendieta y Núñez, 1979: 58-63). Las reflexiones de Forjando patria (pro nacionalismo) dejaron una huella profunda en los procesos de profesionalización e institucionalización y en el quehacer de la antropología mexicana desde finales de la década de 1910 hasta entrada la segunda mitad del siglo $\mathrm{xx}^{3}$ Con el apoyo del secretario de Agricultura y Fomento, el carrancista Pastor Rouaix (González, 1987: 48), Gamio fundó y dirigió la Dirección de Antropología de la Secretaría de Agricultura y Fomento de México de 1917 a 1924 (Hewitt de Alcántara, 1988: 25). En dicha institución desarrolló las investigaciones multidisciplinarias que desembocaron en La población del Valle de Teotihuacán (1922) (Schmidt, 1978: 109). ${ }^{4}$ En la "Introducción" de La población del Valle de Teotihuacán, Gamio retomó y dio continuidad a las ideas y propuestas académicas y nacionalistas ya formuladas en Forjando patria (pro nacionalismo) para orientar las tres líneas de acción de la Dirección de Antropología: 1) obtención de los conocimientos "raciales, [...] lingüísticos, culturales, económicos y de entorno natural de las poblaciones de México" (Gamio, [1916] 1922: 10), especialmente las indígenas;

\footnotetext{
Panamericano de Washington, Gamio, en su carácter de presidente de la delegación mexicana (González, 1987: 48), sugirió la conformación de instituciones científicas - direcciones de Antropología - a lo largo del continente, con el propósito de investigar las realidades y problemas sociales de los países americanos (Gamio, [1916] 1992: 19; Mendieta y Núñez, 1979: 59).

${ }^{3}$ En 1960 se realizó la segunda edición de Forjando patria (pro nacionalismo). Para ese tiempo todavía la teoría culturalista estadounidense, que Gamio introdujo a México, era uno de los paradigmas predominantes de la práctica de la antropología —académica e indigenista- (Medina, 1983: 27).

${ }^{4}$ Esta obra fue premiada internacionalmente en la Exposición Ibero-Americana de Sevilla (1930) y en la Exposición Internacional del Centenario de Río de Janeiro (1922), y se convirtió en un referente de investigaciones antropológicas de carácter integral (Mendieta y Núñez, 1979: 65-67).
} 
2) indagación de los medios pertinentes y prácticos para que las instituciones gubernamentales pudieran "fomentar efectivamente el actual desarrollo físico, intelectual, moral y económico de dichas poblaciones [indígenas]" (Gamio, [1916] 1922: 11); 3) preparación de una aproximación "racial, de la fusión cultural, de la unificación lingüística y del equilibrio económico de dichas agrupaciones, las que sólo así formarán una nacionalidad coherente y definida y una verdadera patria" (Gamio, [1916] 1922: 11). ${ }^{5}$

En el conjunto de la obra de Gamio, Forjando patria (pro nacionalismo) fue especialmente relevante por ser el antecedente obligado de otras dos obras fundamentales de este antropólogo: Hacia un México nuevo. Problemas sociales (1935), publicada a principios del cardenismo, cuando Gamio era asesor del proyecto educativo socialista (González, 1987: 108109), en la que detalló y amplió las reflexiones y líneas de acción -lingüísticas, culturales, económicas y étnicas - del programa integracionista esbozado en Forjando patria (pro nacionalismo) (Gamio, 1987: 19-23); y Consideraciones sobre el problema indígena (1948), texto en el que, además de un programa de propuestas indigenistas concretas en materia de economía, alimentación, salud y cultura por el III (Comas, 1975: 48-49; Gamio, 1966: 5-14, y 1987: 104, 132), Gamio expuso como objetivo esencial del III la satisfacción de las necesidades y aspiraciones culturales, económicas y sociales de los grupos indígenas (Aguirre, 1992: 131-132; Gamio, 1966: 1-3). Esta obra puede ser leída como un recuento del ideario y del quehacer del III durante sus primeros seis años de existencia (1942-1948).

Más allá de sus reflexiones en torno a la diversidad cultural y sus propuestas concretas sobre los

\footnotetext{
${ }^{5}$ Esta obra sobre Teotihuacán y su labor en la Dirección de Antropología mostraron cómo Gamio articuló la producción de conocimiento dirigido - antropología aplicada - y las políticas del Estado (Schmidt, 1978: 109). En esta línea reflexiva, Olivé Negrete consideró que la Dirección de Antropología, cuyos propósitos, según este antropólogo, fueron avanzar a la unificación cultural y el equilibro económico de la población como mecanismos para edificar la nacionalidad y la patria, fueron el origen de la escuela mexicana de antropología aplicada (Olivé, 2000).
}

indígenas, Gamio manifestó una constante preocupación por la mejoría de las condiciones materiales de vida de los pueblos indios (Basave, 2006: 126). ${ }^{6}$ Las reflexiones y propuestas de Forjando patria (pro nacionalismo), pero también de Hacia un México nuevo y de Consideraciones sobre el problema indíge$n a$, fueron una influencia significativa para el ideario del indigenismo mexicano de gran parte del siglo $\mathrm{xx},{ }^{7}$ en especial si se considera que el proceso de integración -lingüístico, cultural, étnico y económico esbozado inicialmente en Forjando patria (pro nacionalismo) (Gamio, [1916] 1992: 183) — fue retomado parcial y selectivamente por los encargados del diseño y la realización de las políticas de Estado hacia los indígenas en el siglo pasado. Palerm señalaba a este respecto que "la política oficial frente al indio ha sido siempre integracionista” (Palerm, 1976: 12) ${ }^{8}$ y en

\footnotetext{
${ }^{6}$ Para Agustín Basave la mejora de las condiciones de vida material de los indígenas era un rasgo distintivo de Gamio: "A diferencia de sus predecesores, el interés [de Gamio] por el bienestar del indio -vis a vis el del criollo o el de la nación en su conjunto- ocupa un lugar preeminente en su cruzada a favor del mestizaje. [...] Más allá de sus afanes retóricos, está claro que se trata de una preocupación tan auténtica como desesperanzada" (Basave, 2006: 126).

${ }^{7}$ Por su conocimiento personal y cercanía con Gamio destacan dos personas: Lucio Mendieta y Núñez, quien trabajó con Gamio en la Dirección de Antropología y a la postre fue director del Instituto de Investigaciones Sociales de la Universidad Nacional Autónoma de México (UNAM), donde desarrolló investigaciones de sociología rural (Mendieta y Núñez, 1979: 65), y Gonzalo Aguirre Beltrán, uno de los principales ideólogos y teóricos del indigenismo oficial, quien colaboró con Gamio en la década de 1940 (Palerm, 1976: 11), y posteriormente fue director del III y del Instituto Nacional Indigenista (INI).

${ }^{8}$ En la "Introducción" al texto Aguirre Beltrán: obra polémica (1976), Ángel Palerm reflexiona sobre las políticas del Estado y otras instituciones - sociales, políticas y religiosas- hacia los indígenas y comenta: "De cualquier manera, la política oficial frente al indio ha sido siempre integracionista, y cuando digo siempre quiero decir desde la Conquista. Bajo diferentes banderas ideológicas, con diversidad de actitudes y propósitos, se ha tratado constantemente de integrar al indio. Integrar ha significado, sucesivamente o al mismo tiempo, cristianizar, castellanizar, occidentalizar; o bien, dicho en otro lenguaje, extraer al indio de su comunidad y convertirlo en peón de hacienda, en minero, en criado doméstico, en trabajador migratorio, en asalariado urbano, etc. Desde el siglo pasado, en particular, integrar exige mexicanizarlo, hacer que pase a formar parte de la sociedad nacional, tanto cultural como social, política y económicamente" (Palerm, 1976: 12).
} 
1976 apunta que la teoría y la praxis del indigenismo mexicano - del Instituto Nacional Indigenista (INI) - habían sido elaboradas sobre todo por Gamio y Aguirre Beltrán (Palerm, 1976: 18). En Forjando patria (pro nacionalismo), entre otros, Gamio trató tres tópicos significativos: 1) el balance y la crítica del sistema jurídico-político mexicano de principios del siglo xx y su relación con los grupos étnicos; 2) las características de una nacionalidad definida e integrada, la propuesta integracionista $y$ su relación con los pueblos indígenas, y 3) la antropología como práctica epistémica-política en la reconstrucción de México. Se abundará en cada uno de estos temas en las siguientes secciones.

\section{CRÍTICA DEL SISTEMA JURÍDICO-POLÍTICO MEXICANO DE INICIOS DEL SIGLO XX}

Para Gamio, la crítica al cuerpo de leyes mexicanas de inicios del siglo $\mathrm{xx}$ se fundaba en dos principios prescriptivos que, a su juicio, toda legislación debía contener y de los que carecía la Constitución mexicana vigente hasta antes de 1916. El primero es el principio esencial de que toda ley tenía que representar la satisfacción de las necesidades y aspiraciones de la población, así como la gestión del bienestar físico, moral e intelectual de la misma (Gamio, [1916] 1992: 71). ${ }^{9}$ En segundo término, la Constitución, a través del conocimiento generado por la antropología y la sociología en torno a la población, debía considerar los diversos grupos socioculturales que componían

\footnotetext{
${ }^{9} \mathrm{El}$ autor cuestionaba la organización política del gobierno mexicano a inicios del siglo xx por tres razones: 1) sólo representaba y reflejaba las necesidades, aspiraciones y anhelos del grupo poblacional de origen europeo con privilegios económicos y políticos; 2) no se consideraba ni se representaba a los indígenas, se les obligaba a vivir de acuerdo con normas y preceptos ajenos a ellos (Gamio, [1916] 1992: 11), y 3) la desigualdad económica permitida por el orden político de finales del siglo xIX y principios del $\mathrm{xx}$, que se traducía en la excesiva riqueza de unos y en las paupérrimas condiciones de vida de los grupos étnicos, era otro obstáculo a la idea de patria y nacionalidad.
}

al país, a fin de elaborar leyes acordes con las realidades sociohistóricas de cada uno. Este aspecto cobraba relevancia por el hecho de que en el México de principios del siglo $\mathrm{xx}$ los diversos grupos indígenas y de ascendencia indígena conformaban la gran mayoría de la población. Según el Censo de Población de 1910, de los 15160000 habitantes en el país, sólo 4\% residía en localidades de más de 100000 personas - que eran las ciudades de Guadalajara y México-, mientras 71\% de los mexicanos vivía en poblados con menos de 2500 habitantes (INEGI, 1996: 17). Por su parte, en Forjando patria (pro nacionalismo), Gamio subrayó que había entre "ocho y diez millones de individuos de raza, de idioma, y de cultura o civilización indígena" (Gamio, [1916] 1992: 9).${ }^{10}$ Además, la importancia de los grupos étnicos no residía sólo en la fusión de la significación demográfica - el número de habitantes total que abarcaban los indígenas-, sino también en su peso político e histórico, debido a que estos grupos habían sido, a lo largo de la historia de México, estructural y sistemáticamente explotados y marginados. El olvido y la discriminación constantes hacia los indígenas era un problema político y social que debía solucionarse.

El punto anterior era impostergable, de otra manera, a semejanza de lo acontecido en la Constitución de 1857 y las Leyes de Indias en la Colonia, se mantendría la brecha anacrónica entre una Constitución desfasada - poco representativa de la mayoría de la población- y el olvido en que se encontraban grandes sectores de los habitantes de México, en especial los grupos indígenas. La contraparte de este hecho era una Constitución que únicamente representaba y estaba en función de una minoría: el sector de la población con ascendencia europea directa e indirecta, principalmente descendientes de españoles.

\footnotetext{
${ }^{10}$ Respecto de cuántos de los campesinos eran indígenas, los datos son discordantes. Vera Estañol, secretario de Instrucción Pública y Bellas Artes en 1911, señaló que había 6000000 de indígenas (citado en Zúñiga, 2011: 187). Por su parte, Engracia Loyo, de acuerdo con el criterio lingüístico del censo de 1910, apuntó la existencia de 3000000 (Loyo, 2011: 154).
} 
Aparejado a lo anterior, debido a que a decir de Gamio el orden jurídico era una réplica de los sistemas legales europeos (Gamio, [1916] 1992: 72), había una clara falta de correspondencia entre el diseño y cuerpo de la Constitución mexicana de finales del siglo xix y la historia y la conformación sociodemográfica del país en esa época. ${ }^{11}$ Esto no sólo manifestaba un problema de representatividad política y de un Estado parcial y selectivo, sino que se añadía el componente del uso preferencial de recursos y beneficios económicos para el grupo minoritario de la población con ascendencia europea. Según el autor, la mayoría de los países latinoamericanos se encontraban en situaciones similares. En relación con los cambios acontecidos en los gobiernos carrancistas y en el contexto de los preparativos y debates para la elaboración de la Constitución de 1917, Gamio señalaba:

era preciso que un gobierno democrático considerara con mayor detenimiento el problema de la población nacional y de la Constitución que debería de convenirle (Gamio, [1916] 1992: 73).

Esta medida tendría que extenderse a gran parte de los países de América, sobre todo aquellos con grupos étnicos:

Sugiérase a las Repúblicas latinoamericanas, en las que predomina la población indígena, la conveniencia de revisar las Constituciones vigentes, a fin de que respondan a la naturaleza y necesidades de todos los elementos constitutivos de la población y pueda alcanzarse el desarrollo armónico e integral de la misma, fortaleciéndose así, positivamente, lo que es la base del verdadero panamericanismo (Gamio, [1916] 1992: 73).

\footnotetext{
${ }^{11}$ Gamio criticaba la importación, por parte de las elites econó mico-políticas, de modelos jurídico-políticos europeos y estadounidenses discordantes con la historia y con la realidad social y étnico-cultural del país (Gamio, [1916] 1992: 30). Además, debido a las condiciones y características compartidas con gran parte del continente, el caso de México era representativo e ilustraba lo acontecido en el resto de los Estados latinoamericanos (Gamio, [1916] 1992: 9, 71-72).
}

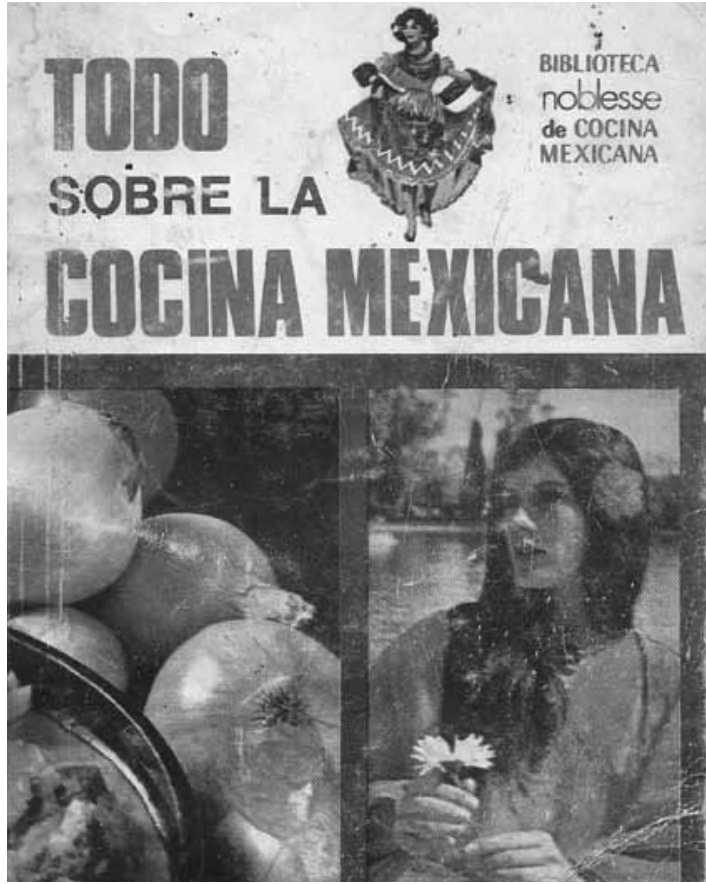

Todo sobre la cocina mexicana, 1975. La foto de un platillo no identificable adquiere un significado de nacionalidad al ir acompañado de una imagen prototípica de la belleza nacional: una mujer vestida al modo indígena posa en los canales de Xochimilco.

Gamio tenía una postura de clara mesura respecto de modelos universalistas legales, con base en leyes generales y únicas de aplicación irrestricta a todos los habitantes, independientemente de las diferencias socioculturales constitutivas de los variados grupos de un país. En este sentido, el conocimiento antropológico de la población y su diversidad, al servicio de gobiernos íntegros, proveería las herramientas para establecer un orden jurídico con un fundamento legal común, lo que a su vez permitiría la instauración de leyes específicas dirigidas y acordes con cada uno de los sectores de la población y sus peculiares contextos históricos y socioeconómicos (Gamio, [1916] 1992: 31). No obstante, no todo se limitaba a la relación entre la Constitución, la conformación y las características de los grupos socioculturales de la población. Había otro aspecto base y de orden político muy vinculado a la necesidad de una reforma del sistema legal de principios 
del siglo xx: la cuestión de cuál debería ser el perfil ideal y normativo de quienes en el futuro serían los representantes del pueblo en el Poder Legislativo (Gamio, [1916] 1992: 75). Esto cobraba relevancia en la medida en que, después de un balance de las Cámaras del Legislativo y su manera de proceder, Gamio encontraba severos vicios tanto en la conformación de los cuerpos legislativos como en la integridad moral de las personas que los constituían.

La cuestionable legitimidad del sistema estatal y legal tenía como base un conflicto de representatividad política y jurídica que tocaba dos ejes. Uno de carácter geopolítico al interior del país, donde había una preeminencia de ciertas regiones sobre otras, que mostraba ya un problema claro de centralismo. Gamio subrayaba que sólo de "manera teórica y nominal" (Gamio, [1916] 1992: 75) se representaba a las regiones y centros políticos de todo el país. Mientras que algunas entidades - como la ciudad de México- contaban con una fuerte y contundente presencia de legisladores en el Senado y la Cámara popular, la mayoría de los estados tenían como representantes a personas que no eran originarias ni conocían las condiciones de vida de las regiones que representaban, lo que condujo a "dar cierta preeminencia política, aun cuando fuese virtual, a algunos centros y regiones con perjuicio de otros" (Gamio, [1916] 1992: 75). El otro eje remitía al carácter diacrónico del Estado y tenía que ver con la historia y el funcionamiento peculiar de los regímenes liberal y porfirista. Durante el Porfiriato los legisladores, a decir de Gamio, tuvieron un papel pasivo y sólo servían para legitimar, con su carencia de agencia, el perfil no democrático de ese gobierno. Vinculado a esto, cuestionaba la pertinencia y alcance de las leyes del México independiente, en tanto que no habían generado el desarrollo armónico de los diversos grupos sociales del territorio nacional y tampoco propiciaron el progreso equitativo y simultáneo de las entidades federativas de México durante el siglo xIx y principios del xx. En resumen, el balance sobre la política era crítico y claramente negativo, denunciaba los problemas y carencias de dicho entorno, tanto en la estructura como en sus individuos.

Frente a este escenario, Gamio planteó una serie de medidas concernientes a la composición y los criterios de representación sobre los grupos e individuos que formaban las Cámaras. Dichas medidas generarían las condiciones de legitimidad democrática necesarias para que los legisladores cumplieran a cabalidad sus cargos de representantes, e iban dirigidas básicamente a la incorporación de diversos grupos sociales que no habían sido representados con suficiente relevancia en el Poder Legislativo. Gamio consideraba que era indispensable consolidar una representación étnica, en especial en el contexto sociodemográfico del país, compuesto en su mayoría por grupos indígenas. Para este autor ellos mismos deberían elegir a sus representantes (Gamio, [1916] 1992: 76). Los procedimientos electorales, sin contravenir los lineamientos generales, serían los que ellos mismos eligieran de acuerdo con su contexto y modo de vida, y sin perjuicio de la colectividad (Gamio, [1916] 1992: 76). ${ }^{12}$ Era imprescindible la búsqueda de una representación más equitativa de los grupos socioeconómicos en las Cámaras. Éstas no deberían estar conformadas exclusivamente por personas de los sectores económicos favorecidos, sino también por:

obreros de las ciudades, braceros de los campos, burócratas, industriales, agricultores, capitalistas, gentes de mar, ferrocarrileros, etc., etc., deben poseer, efectivamente, voz y voto en materia de legislación (Gamio, [1916] 1992: 77).

Con ello se garantizaría que las leyes no beneficiaran sólo a un grupo, sino que incluyeran las necesidades,

\footnotetext{
${ }^{12}$ Gamio plantea que el orden jurídico por venir y la nueva estructura política - que daría solución a los históricos reclamos de la Revolución- debían estar en función de la historia y la compleja conformación étnica, cultural y sociodemográfica de México de principios del siglo xx (Gamio, [1916] 1992: 71-78). Opta por hacer converger en una "nacionalidad coherente y definida" (Gamio, [1916] 1992: 8) a los diversos grupos de un México marcado por la desigualdad, la exclusión y la marginación.
} 
los anhelos y las aspiraciones de todos. En la política institucional hacía falta la presencia de hombres de ciencias, de humanidades y de artes. El aporte de estos individuos era fundamental para el progreso de México (Gamio, [1916] 1992: 76-77).

\section{APROXIMACIÓN Y RASGOS DE UNA NACIONALIDAD DEFINIDA E INTEGRADA}

En Forjando patria (pro nacionalismo) Gamio expresa que la necesidad de la creación de una nueva patria con una "nacionalidad definida e integrada" era producto de una larga génesis temporal y se fundaba en la deuda histórica, postergada durante siglos, que como país se tenía con enormes contingentes de la población: los grupos indígenas. Señala que desde la Conquista hasta la etapa final del Porfiriato los grupos indígenas, pese a haber contribuido con su sangre a los procesos de cambio, no habían sido incorporados de manera activa en el concierto de la vida política, económica y social del país (Gamio, [1916] 1992: 5-6). Por el contrario, se les había recluido en el olvido. Sin embargo, en el marco del movimiento constitucionalista de Carranza (1916), Gamio pensaba que la Revolución Mexicana era la ocasión para saldar tal deuda y construir una nación con la contribución de los grupos socioculturales del país. En la búsqueda de Estados que mostraban una "verdadera nacionalidad" (Gamio, [1916] 1992: 8), alude únicamente a Alemania, Francia y Japón como los modelos a seguir. Estos países presentaban tres características comunes que los distinguían como naciones consolidadas. El primer eje, que para Gamio revestía una importancia capital, tenía que ver con la conformación de la población. El grueso de los habitantes de estos países tenía una ascendencia étnica más o menos común, además de características fenotípicas y rasgos biológicos semejantes entre sí (Gamio, [1916] 1992: 8). Paradójicamente, para Gamio, antropólogo formado en el particularismo histórico boasiano, que reivindicaba la diferencia cultural y criticaba el uso del término "raza" y el determinismo biológico (Boas, 1964), el proceso de mezcla biológico que daría lugar a la unificación de las características fenotípicas era una piedra angular en la constitución de una "nacionalidad definida e integrada" (Gamio, [1916] 1992: 8). Las siguientes palabras sobre el mestizaje en Yucatán no dejan lugar a dudas:

Pues bien, esta homogeneidad racial, esta unificación del tipo físico, esta avanzada y feliz fusión de razas, constituye la primera y más sólida base del nacionalismo" (Gamio, [1916] 1992: 13). ${ }^{13}$

El otro rubro que caracterizaba a una nacionalidad definida e integrada aludía a una base comunicativa franca y efectiva. No obstante la existencia de otros idiomas -o "dialectos secundarios" (Gamio, [1916] 1992: 8) —, era fundamental el uso de una lengua común semejante a todos (Gamio, [1916] 1992: 8). Por último, a pesar de la especificidad propia de sus regiones, estos países poseían en común una serie de prácticas culturales - “costumbres"-, de objetos materiales, de creencias y valores, así como el hecho de compartir una historia y conciencia del pasado relativamente semejante (Gamio, [1916] 1992: 8). Según Gamio, las tres características descritas daban un sentido de coherencia y cohesión a la población de esos países, que se asemejaba a una gran familia extendida en la que privaban los lazos de hermandad y se presentaba una enorme similitud entre todos sus miembros (Gamio, [1916] 1992: 8-9). El hegemónico dominio de la homogeneidad y la consecuente postergación de los rasgos diferenciadores y particularizantes eran la base sobre la que se fundaba esta idea de nación; la exclusión y la discriminación velada y/o explícita de lo distinto, de

\footnotetext{
${ }^{13}$ Esto permite trazar una línea de semejanza con lo planteado por Hobsbawm, quien en una lectura genealógica de la historia de los Estados nacionales de Europa Occidental entre finales del siglo XIX y principios del $\mathrm{xx}$ registra que para varios de estos países la supuesta idea de la homogeneización étnica fue un rasgo fundamental para identificarse como naciones por venir. El otro tipo de nacionalismo que describió fue el de corte lingüístico (Hobsbawm, 2000: 109-140).
} 
los "otros" - los diversos, los diferentes-, estaba en el eje nodal de la génesis de esta concepción sobre la nacionalidad de cepa occidental europea. Sin embargo, la población de México de mediados de la década de 1910 distaba con creces de lo descrito para los casos de Francia, Alemania y Japón. México era un país predominantemente rural y los grupos indígenas, con contextos histórico-culturales diferentes a los de Europa, conformaban un enorme sector demográfico. En Forjando patria (pro nacionalismo), Gamio anota que las familias indígenas integraban "mucho más de la mitad de la población" (Gamio, [1916] 1992: 104). Había "ocho o diez millones de individuos de raza, de idioma y de cultura o civilización indígena” (Gamio, [1916] 1992: 9), mientras que sólo habitaban en el país "seis o cuatro millones de seres de origen europeo" (Gamio, [1916] 1992: 9), sin especificar si se refería a los mestizos y/o a hijos de europeos. No había, pues, una nación en el sentido previamente descrito y cuyo modelo se remontaba a Europa.

1184 En cambio, el autor asentaba la existencia de pequeñas patrias, divididas en dos clasificaciones: 1) aquellas en las que únicamente habitaban indígenas, caso en el que se encontraban los yaquis, los mayas y los huicholes (Gamio, [1916] 1992: 12), y 2) otras en las que se había llevado a cabo el cruzamiento entre los indígenas y los grupos de ascendencia europea, como Yucatán (Gamio, [1916] 1992: 12), para Gamio el ejemplo a nivel regional de lo que tendría que acontecer de manera generalizada en todo el territorio mexicano. ${ }^{14}$ La diversidad

\footnotetext{
${ }^{14}$ Gamio encuentra que varias de las pequeñas patrias -en especial las indígenas y Yucatán, de población mezclada - ya presentaban las características de la nacionalidad definida e integrada. En relación con las pequeñas patrias maya, yaqui y huichol, decía: "estas agrupaciones poseen un nacionalismo claramente definido y caracterizado por sus respectivas lenguas, manifestaciones culturales y naturaleza física" (Gamio, [1916] 1992: 12). Si Gamio ya observaba grupos con una nacionalidad constituida - según los términos de su modelo occidental basado en la cultura, el lenguaje y los rasgos físicos en común-, por qué en vez de proponer un modelo político de país con una sola y homogénea nacionalidad no llegó a sugerir un proyecto de Estado con varias naciones en su interior.
}

-económica, social, cultural, pero sobre todo étnica - caracterizaba a la población. Gamio afirmaba que como país

constituimos un conjunto de agregados sociales étnicamente heterogéneos, cuyo progreso no es sincrónico y no se desarrolla en sendas paralelas sino divergentes (Gamio, [1916] 1992: 23).

Frente a la compleja y variada conformación sociocultural de México de fines de la Revolución y con referencia al modelo de nacionalidad europeo occidental - Francia y Alemania-, Gamio sugirió un ambicioso programa de ingeniería social que consistía en la convergencia de los diversos grupos sociales para crear un conglomerado más homogéneo y con una cultura propia. El proceso de incorporación a este cauce común sería más abrupto y drástico para algunos sectores, principalmente para los indígenas. De aquí surgió la idea de una "cultura intermedia - resultado de las tradiciones prehispánicas y de las del Viejo Continente-" (Gamio, [1916] 1992: 98), que tendría que generalizarse para adquirir el carácter de nacional. La cultura intermedia sería uno de los rasgos distintivos y preponderantes del grupo social resultante de la mezcla de los indígenas y el resto de la población, en especial los sectores cuya línea de ascendencia venía del Viejo Continente. ${ }^{15}$ En Forjando patria (pro nacionalis$m o$ ), Gamio formula diversas y ambiguas valoraciones sobre las diferencias socioculturales tanto de los grupos de origen extranjero - a quienes imputaba su desfase de la realidad social e histórica de

\footnotetext{
${ }^{15}$ Estos planteamientos de Gamio, con sus ideas de "fusión de razas, convergencia y fusión de manifestaciones culturales" (Gamio, [1916] 1992: 183) del final de Forjando patria (pro nacionalismo), probablemente pueden considerarse como antecedentes de las ideas del mestizo y el mestizaje que marcaron profundamente la vida sociocultural del México posrevolucionario de buena parte del siglo xx. Es significativo que Forjando patria (pro nacionalis$m o$ ), con un planteamiento más armado sobre las dinámicas de mezcla entre los sectores demográficos, se publicara nueve años antes que La raza cósmica de Vasconcelos, obra que se convirtió en un "emblema" de las manifestaciones culturales del siglo pasado.
} 
México- como de los grupos indígenas. En particular a los indígenas, pese a los elogios por sus "mayores energías y resistencias físicas” (Gamio, [1916] 1992: 10) y por el hecho de poseer "iguales aptitudes para el progreso que el blanco" (Gamio, [1916] 1992: 24), Gamio les atribuía un "estancamiento cultural" (Gamio, [1916] 1992: 10) y afirmaba que tenían:

un retraso de 400 años, pues sus manifestaciones intelectuales, no son más que una continuación de las que se desarrollaban en tiempos prehispánicos (Gamio, [1916] 1992: 94).

Más adelante, en el capítulo "Nuestra cultura intelectual", Gamio detalla sus consideraciones sobre el modo de vida, la cultura y tradición indígenas:

\footnotetext{
El indio posee una civilización propia, la cual, por más atractivos que presente y por más alto que sea el grado evolutivo que haya alcanzado, está retrasada con respecto a la civilización contemporánea, ya que ésta, por ser en parte de carácter científico, conduce actualmente a mejores resultados prácticos, contribuyendo con mayor eficacia a producir bienestar material e intelectual, tendencia principal de las actividades humanas (Gamio, [1916] 1992: 96).
}

La civilización indígena, además de ser retrasada con relación a la occidental, no estaba sistematizada, no formaba escuela, la guardaban y cultivaban las masas, no tenía vulgarizadores profesionales, se la dejaba propagarse espontáneamente. En cambio, la cultura europea, además de presentar un grado evolutivo más avanzado, era difundida metódica y científicamente, si cabe la expresión y se consideran la época y las circunstancias (Gamio, [1916] 1992: 97).

En este punto, más que propugnar por un efectivo respeto y reconocimiento de la historia, tradiciones y culturas de los grupos indígenas - banderas del legado antropológico de su maestro Boas (Harris, 1979: 218-219)—, Gamio optó por un integracionismo progresivo que apuntaba hacia la consolidación de un gran grupo homogéneo y que se caracterizaría por la unificación cultural y una sola lengua. Por otro lado, aunado a su valoración del anacronismo de la civilización indígena para la época, caracterizó a los indígenas de principios del siglo xx como grupos carentes de las capacidades, los anhelos y las directrices necesarias para llevar a cabo por ellos mismos el cambio de sus condiciones de vida (Gamio, [1916] 1992: 94). Según Gamio, eran sujetos con una limitada agencia, construidos simbólicamente en términos de grupos desvalidos y victimizados, quienes necesitaban de ayuda externa -léase de antropólogos, sociólogos, etc.- para modificar su adversa e inequitativa situación e incorporarse a la vida nacional. En este sentido, el autor aseveraba:

¡Pobre y doliente raza! [...]. No despertarás espontáneamente. Será menester que corazones amigos laboren por tu redención. La magna tarea debe comenzar por borrar en el indio la secular timidez que lo agobia (Gamio, [1916] 1992: 22).

En esta parte es conveniente preguntarse, aun pese a que Gamio reconocía cierta relevancia y valía en algunos productos artísticos y prácticas culturales indígenas, ¿hasta qué punto en sus representaciones sobre los indígenas reproducía estigmas y prejuicios que sobre estos grupos tenían ciertos sectores de las clases medias-altas urbanas con educación universitaria? No obstante, en Forjando patria (pro nacionalismo), Gamio no se quedó en el nivel discursivo del diagnóstico sobre la historia, la cultura y las condiciones de vida de los indígenas, también delineó una propuesta de cambio. Planteó un proceso de integración progresivo en cuatro rubros: 1) La población y su futura reconfiguración: los diversos grupos sociales y étnicos tendrían que mezclarse entre sí, para avanzar hacia la conformación de un nuevo sector - resultado de los indígenas y aquellos grupos de origen europeo-. Éste era, sin usar la terminología de otros autores - como Vasconcelos en La raza cósmica (Vasconcelos, 2010: 4-35)—, el proyecto del mestizo y el mestizaje. En repetidas ocasiones y con especial insistencia al final de Forjando patria (pro nacionalismo), habló con acuciante reiteración de la indispensable "fusión de razas" (Gamio, [1916] 
1992: 183). La mezcla ocurriría, entre otros aspectos, a nivel de los rasgos biológicos - de fenotipo- - 2) Otro eje era la confluencia de las prácticas y expresiones culturales materiales e inmateriales -valores, creencias - de los variados grupos sociales de México, para amalgamar tradiciones disímiles en un solo conglomerado que produjera la "cultura nacional", que tendría un carácter homogéneo. 3) También era necesaria una base comunicativa común, el establecimiento del español como lengua franca - hablada por todos los mexicanos-y con un carácter nacional. Gamio recalcó la relevancia de un proceso de "unificación lingüística" (Gamio, [1916] 1992: 183), lo que no impedía que ciertos grupos de la población hicieran uso de sus lenguas originarias, pero éstas tendrían un carácter secundario. 4) Finalmente, era indispensable un proceso que modificara los modos de producción y distribución de bienes materiales, que condujera a una mayor equidad e igualdad económica entre los diversos grupos de México de principios del siglo xx. La ur-

gente pertinencia de un "equilibrio económico de los elementos sociales" (Gamio, [1916] 1992: 183), que conllevaría un bienestar generalizado a los diversos sectores de la población y revertiría la desigualdad estructural que había caracterizado la historia de México a lo largo de los siglos. Ésta era una forma de establecer la armonía social necesaria para la conformación de la nacionalidad.

La dinámica de convergencia social previamente descrita tuvo dos puntos de tensión. Por un lado, por paulatino que fuera y aun con la anuencia de los grupos indígenas, el proceso integracionista propuesto por Gamio para principios del siglo xx suponía, ya fuera implícita y atenuadamente, un contundente proceso de cambio sociocultural que implicaba desde la inserción de una lengua franca hasta la modificación de actividades tradicionales de raíz prehispánica y la incorporación de prácticas de corte occidental y modernas, como el uso de las ciencias y las tecnologías de las sociedades industriales europeas y norteamericanas. Para ser "incorporados" al concierto

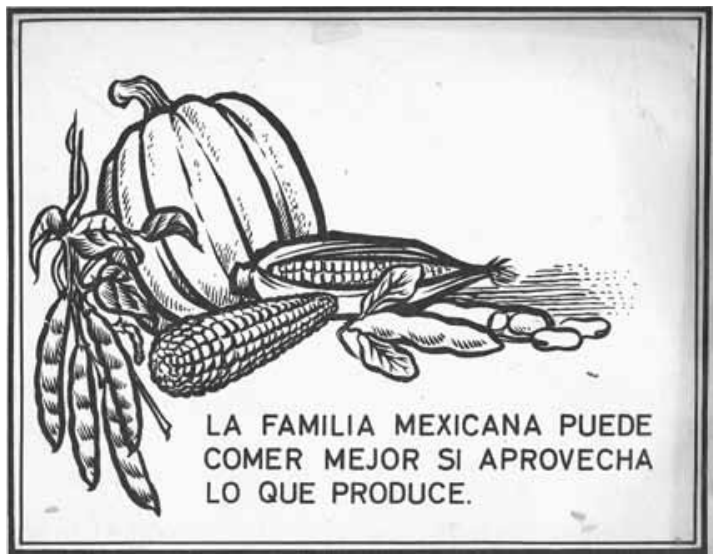

Eslogan impreso en la contraportada del recetario Cómo enriquecer los alimentos con la harina de soya, 1964.

nacional y tener "el carácter de mexicanos", los indígenas tendrían que dejar tras de sí buena parte de las prácticas, valores y creencias que los definían como grupos con una historia y tradición propia. Por otra parte, si bien Gamio trató diversos rubros en el proceso de incorporación de los indígenas - la lengua, la cultura, la economía-, en su propuesta práctica integracionista no consideró con suficiente claridad la cuestión de las significativamente desiguales relaciones de poder entre los indígenas, otros grupos sociales y el Estado. No detalló con precisión qué aportaría cada grupo - los indígenas y los no indígenas- ni en qué términos y bajo qué condiciones se llevaría a cabo la "fusión". Más que un intercambio equitativo destinado a la generación de un nuevo grupo con múltiples y variadas influencias tradiciones-, la "fusión" era una posible imposición, paulatina y no violenta, de diversas prácticas -sociales, culturales, económicas y productivas- a los grupos étnicos, con lo cual se reproducía la desigualdad y la discriminación hacia ellos.

En esta iniciativa tampoco se encuentra una cabal consideración de los indígenas como sujetos históricos y como grupos con derechos postergados. Aunque los grupos étnicos eran receptores y "beneficiarios" del cambio, su papel activo y su agencia en 
el proceso de transformación estaba bastante desdibujado, lo que concuerda y se explica, además, en función de la valoración de Gamio sobre los indígenas como grupos con falta de "aspiraciones" (Gamio, [1916] 1992: 21) y carencia de "dotes directivas" (Gamio, [1916] 1992: 94), que por tanto requerían de la ayuda externa para salir de su condición (Gamio, [1916] 1992: 22). Dentro de las reflexiones sobre el nacionalismo, la idea de la constitución de un núcleo duro cultural común como sustrato de la nacionalidad a construir, que en el caso de Gamio incorporaría la unificación lingüística y la conformación de prácticas socioculturales homogéneas mediante la fusión de las raíces indígena y europea, tenía una significativa semejanza con la descripción cultural de nación que Gellner, en Naciones y nacionalismo, estudió y calificó de insuficiente en la búsqueda de una teoría sobre el nacionalismo (Gellner, 1994: 20, 77). Al elaborar la definición cultural de nación, Gellner escribe:

dos hombres son de la misma nación si y sólo sí comparten la misma cultura, entiendo por cultura un sistema de ideas y signos, de asociaciones y pautas de conducta y comunicación (Gellner, 1994: 20).

Pero en Forjando patria (pro nacionalismo), a principios del siglo $\mathrm{xx}$, no hallamos el sustrato cultural común aún como resultado de la historia de México ni como producto de la convivencia entre los diversos sectores de la población. Hasta ese momento, ni la idea de nación - y su realización práctica - ni su correspondiente basamento - la cultura compartida- eran producto del devenir histórico-político del país. Por el contrario, la concepción de nación era un constructo, un proyecto de ingeniería social desde la idea de Gamio sobre lo que debería ser el Estado y sus características socioculturales y las de sus habitantes. En su peculiar lectura de la historia de México, este autor incrustó el telón de la homogeneización social como camino para forjar patria, la idea de que el destino de México era forzosamente constituirse en una sola nación, dentro de un solo Estado. ${ }^{16}$ Desde la economía política de las representaciones que delinearon Forjando patria (pro nacionalismo), la nación "aparecía" como el ineludible proyecto de convergencia social y cultural que estaba por llevarse a cabo finalmente, era una suerte de destino manifiesto. No deja de ser paradójico además que mientras en la conformación del orden jurídico y del sistema legal Gamio asentara el derrotero de seguir un camino propio basado en la historia particular de México en el caso de la construcción cultural de la nación, en la delineación de su proceso integracionista recurriera a fórmulas ajenas y modelos extranjeros de corte colonialista y de cepa occidental - europea-. La recuperación de un modelo de nación -en esencia, francés y alemán- basado en la homogeneización étnico-demográfica, social, cultural y lingüística, por sutil que fuera, iba en oposición al culturalismo y al particularismo histórico que habían marcado el pensamiento de Gamio durante su estancia en Columbia con Boas (Gamio, 1942: 37).

Otra vía para abordar el análisis de las ideas de nacionalidad y nación en Forjando patria (pro nacionalismo) son las reflexiones de Elie Kedourine formuladas en Nationalism ([1960] 1993). Desde la aproximación de la historia de las ideas (Hutchinson y Smith, 1994: 47), Kedourine considera que el nacionalismo, más que un fenómeno universal, fue resultado del pensamiento europeo de los siglos XIX y xx (Kedourine, [1960] 1993: 68). Desde una perspectiva crítica, señala que para la doctrina nacionalista la lengua, la raza, la cultura, y a veces la religión son diferentes aspectos de una misma entidad fundamental: la nación (Kedourine, [1960] 1993: 67). Si bien hay vaguedad respecto de la clasificación de los nacionalismos de acuerdo con alguno de estos aspectos, lo que está fuera de duda es que esta doctrina

\footnotetext{
${ }^{16}$ Pero, como advierte Gellner, si bien pareciera que toda nación supone - la preexistencia de- un Estado, la ecuación inversa no es exacta. No todos los Estados son naciones (Gellner, 1994: 18) y hay naciones sin un Estado propio (Gellner, 1994: 19-20).
} 
divide a la humanidad en naciones separadas y distintas, que deben constituirse en Estados soberanos y que los miembros de la entidad nacional obtienen libertad y plenitud al estimular la particular identidad de su nación e integrar a familiares y personas cercanas en el recipiente de la nación (Kedourine, [1960] 1993: 67). ${ }^{17}$ Para Kedourine, contra toda evidencia histórica, los creadores de la doctrina nacionalista se esforzaron por demostrar que las naciones eran divisiones naturales, dadas y evidentes "de la raza humana" (Kedourine, [1960] 1993: 74), recurrieron al empleo de la antropología, la lingüística y la historia (Kedourine, [1960] 1993: 74) e hicieron uso del pasado para subvertir y justificar el presente (Kedourine, [1960] 1993: 71). ${ }^{18}$

En una relación de cierta semejanza con las doctrinas nacionalistas caracterizadas y cuestionadas por Kedourine - por suponer de manera acrítica a la raza, la cultura y la lengua como aspectos de la nación (Kedourine, [1960] 1993: 67)—, Gamio, más desde el propósito político de unificación que a partir de la consideración de la enorme evidencia de la heterogeneidad étnica, estableció que las bases para que México tuviera una "nacionalidad coherente y definida" y se conformara como una "patria poderosa" - en el marco de los referentes francés y alemán de nación (Gamio, [1916] 1992: 8-9)— eran la "fusión de razas", la "convergencia de manifestaciones culturales", la "unificación lingüística" y el "equilibrio económico" (Gamio, [1916] 1992: 183). De este modo, Gamio, en coincidencia con el nacionalismo que hace uso del pasado para subvertir el presente (Kedourine, [1960] 1993: 67; Hutchinson y

\footnotetext{
${ }^{17}$ Más adelante, Kedourine señala que lo que permanece en la doctrina nacionalista es la aserción de que los hombres tienen el derecho de afirmar sus diferencias - reales o simbólicamente construidas- respecto de otros y hacer de estas diferencias su primer principio político (Kedourine, [1960] 1993: 74).

${ }^{18}$ Kedourine precisa que el nacionalismo no puede proveer un recuento satisfactorio del pasado político - de los Estados-, y que a su vez carece de una explicación suficiente de por qué las naciones deben estar separadas unas de otras y conformarse en Estados soberanos (Kedourine, [1960] 1993: 74). El mundo es demasiado diverso para las clasificaciones de las antropologías nacionalistas (Kedourine, [1960] 1993: 74).
}

Smith, 1994: 51), hizo una lectura de la historia del país - de la época prehispánica hasta el Porfiriatoy de la Revolución de 1910 vinculada y referida a su perspectiva de cómo México debía y se convertiría en nación. ${ }^{19}$ Gamio contempló la historia de México como los diversos e interrumpidos esfuerzos e intentos de convergencia social que habían fallado, pero que finalmente culminarían en la Revolución con el camino hacia la conformación de una nacionalidad integrada y definida (Gamio, [1916] 1992: 5-6, 183). ${ }^{20}$ En este sentido, los conflictos y enfrentamientos de gran parte del siglo xIX y principios del xx tenían su "explicación capital" en la "pugna por crear patria y nacionalidad” (Gamio, [1916] 1992: 6). La Revolución de 1910 fue percibida por Gamio como una coyuntura central en la vida sociopolítica de México. Fue un punto de inflexión histórico y el inicio de una nueva etapa que permitiría sentar las bases de un vasto proceso de integración general ${ }^{21}$

\footnotetext{
${ }^{19}$ No obstante, algunas interpretaciones de Gamio sobre ciertos momentos específicos de la historia de México son peculiarmente llamativas, por no decir polémicas, como su percepción del proceso de conquista e imposición religiosa durante las épocas de la Conquista y la Colonia. Según Gamio: "No impusieron el catolicismo la cortante tizona, ni el Santo Oficio, ni la caridad de las misiones. El catolicismo no se impuso, porque si hubiera sido así, habrían corrido ríos de sangre, y bien sabido es que los intentos de rebelión de la época colonial fueron pugnas por hambre, por tierras, por opresión, por mil causas, pero casi nunca reyertas por móviles religiosos" (Gamio, [1916] 1992: 85).

${ }^{20}$ En el primer capítulo de Forjando patria (pro nacionalismo), cuyo nombre es también "Forjando patria", Gamio percibe los variados periodos - la época prehispánica, la Conquista y la Colonia, el México independiente- de vida social y política de México como conatos de forjar patria -integrar a los diversos grupos-, que si bien habían fracasado, se insertaban y rearticulaban su cauce y potencial de cambio hacia la Revolución como el momento histórico que daría lugar a la prometida y urgente "fusión" de la "raza de bronce" — indígena-y la "raza de hierro" - española- (Gamio, [1916] 1992: 5-6), cuya manifestación sería un amplio proceso de integración.

${ }^{21}$ Las siguientes palabras del inicio de Forjando patria (pro nacionalismo) reiteran las esperanzas que Gamio tuvo respecto del potencial de cambio que representaba la Revolución: "Toca hoy a los revolucionarios de México empuñar el mazo y ceñir el mandil del forjador para hacer que surja del yunque milagroso la nueva patria hecha de hierro [hispano] y de bronce [indígena] confundidos. Ahí está el hierro... Ahí está el bronce... ¡Batid hermanos!" (Gamio, [1916] 1992: 6).
} 
sobre el que se erigiría "la conquista del bienestar nacional” (Gamio, [1916] 1992: 183) y la nación mexicana, que se caracterizaría por una cultura común y homogénea (Gamio, [1916] 1992: 6, 183).

\section{LA ANTROPOLOGÍA COMO PRÁCTICA POLÍTICA EN LA CONSTRUCCIÓN DEL NUEVO ESTADO}

Dentro del proceso integracionista, cuyo cometido era la convergencia social y la consolidación de una "nacionalidad definida e integrada", las disciplinas antropológicas estaban llamadas a desempeñar un papel central. Para Gamio era necesaria una relación de correspondencia entre el gobierno, los grupos sociales y el conocimiento de éstos, en el entendido de que para el ejercicio de un buen gobierno era indispensable no sólo la conciencia de la diversidad sociodemográfica, sino también el conocimiento detallado de ésta, debido a que la población "es la materia prima con que se gobierna y para quien se gobierna" (Gamio, [1916] 1992: 9). De este modo, el conocimiento era un fundamento clave para gobernar, en tanto que sólo teniendo en cuenta las características e historias particulares de los diversos grupos se podrían atender y resolver las necesidades específicas de los variados sectores de la población. Este conocimiento se generaría desde la antropología —en su extenso sentido disciplinar- y la sociología. En la mayoría de los países latinoamericanos, incluido México, la generación de este saber tenía una notoria urgencia en razón de que, a causa de los gobiernos dirigidos por minorías europeizadas - con ascendencia extranjera - y únicamente preocupadas de estimular su propio progreso y desarrollo, buena parte de los grupos indígenas, que representaban una porción bastante considerable de la población, se encontraban en el abandono (Gamio, [1916] 1992: 15).

Así, en el marco de estas reflexiones, la antropología proveería el conocimiento necesario y la caracterización de la naturaleza y las condiciones de la población. Desde la perspectiva de Gamio en Forjando patria (pro nacionalismo), el propósito final de las investigaciones antropológicas no terminaba en la producción académica, sino que residía en esclarecer las necesidades y carencias de la mayoría de la población, en particular de los indígenas, además de colegir y sugerir los medios, las vías y los procedimientos para mejorar sus condiciones de vida e incrementar su bienestar físico e intelectual (Gamio, [1916] 1992: 17-18). En un primer momento, a fin de establecer el diagnóstico inicial de los indígenas, Gamio planteó en el capítulo "La Dirección de Antropología" un procedimiento integral de investigación que llevó a cabo en su papel de director de la Dirección de Antropología de la Secretaría de Agricultura y Fomento (1917-1924) al articular disciplinas variadas como la historia, la lingüística, la antropología, la arqueología y la historia (Hewitt de Alcántara, 1988: 25). Ese capítulo tuvo especial relevancia por dos razones: 1) previo a la publicación de Forjando patria (pro nacionalismo), este texto fue presentado por Gamio en el $2^{\circ}$ Congreso Científico Panamericano celebrado en Washington, Estados Unidos, en 1916, y en él hizo la propuesta de crear en gran parte de los países de Latinoamérica institutos de antropología para indagar las características de sus diversas poblaciones (Gamio, [1916] 1992: 19; Mendieta y Núñez, 1979: 59), y 2) este texto puede considerarse el itinerario programático de lo que fue el eje de acción y la perspectiva de investigación antropológica de la Dirección de Antropología de la Secretaría de Agricultura y Fomento y de Gamio como uno de los antropólogos mexicanos pioneros del siglo xx. A decir de Gamio, esta institución, fundada en 1917, tuvo por cometido principal:

el estudio de la población nacional desde los siguientes puntos de vista y de acuerdo con un depurado criterio antropológico: $1^{\circ}$ Cuantitativamente: Estadística. $2^{\circ}$ Cualitativamente: Tipo físico, idioma y civilización o cultura. $3^{\circ}$ Cronológicamente: Periodos precolonial, colonial y contemporáneo. $4^{\circ}$ Condiciones ambientales: Fisiobiología regional (Gamio, [1916] 1992: 18). 
Así, según la perspectiva de Gamio, excediendo su condición de una mera práctica epistémica y de registro de la diversidad cultural e histórica de los grupos indígenas, la antropología adquirió un carácter de praxis política destinada a coadyuvar en el cambio social hacia la consolidación del nuevo Estado y a contribuir en el proceso de convergencia social que éste requería. Sobre la base de este conocimiento antropológico de la diversidad y necesidades de la población, así como de los mecanismos para elevar su nivel de vida, se asumiría la obligación indispensable de legislar sobre y para la vida social del país, en función de las respectivas diferencias étnicas, culturales y geográficas de los variados sectores de la población a lo largo del heterogéneo territorio mexicano. De este modo, para este autor era un error y un anacronismo pensar en una sola y única ley para toda la diversidad de grupos socioculturales del México de 1916 (Gamio, [1916] 1992: 30). Para Gamio, el quehacer de la antropología abarcó esta diversidad de funciones sobre la base de un severo problema de orden político: los gobiernos no representaban ni garantizaban el ejercicio de los derechos de la mayoría de su población, en la medida en que tanto los órdenes jurídicos como las formas de organización política y social de México y gran parte de los Estados latinoamericanos estaban desfasados y no correspondían a la historia y la cultura de sus habitantes.

\section{CONCLUSIONES}

Este texto recalca que el pensamiento de Gamio en Forjando patria (pro nacionalismo) no fue unitario y que tenía nodos no del todo consistentes entre sí. Más que un texto con una argumentación única sobre el nacionalismo y los grupos étnicos, fue una compilación de artículos y ensayos. Esta obra tuvo tensiones internas entre sus planteamientos. Mientras Gamio criticaba el orden político y legal de la época porfirista por su carácter extranjero, anacrónico y de desfasada imitación que no respondía a las necesidades y características del grueso de la población del México de inicios del siglo xx, en su propuesta de proyecto de nación volvió a los esquemas de pensamiento colonialistas prooccidentales y siguió principalmente los modelos europeos de Francia y Alemania. Por otra parte, el proyecto de nación de Gamio no puede clasificarse sólo como un nacionalismo de corte étnico y/o lingüístico, a semejanza de las experiencias descritas por Hobsbawm en los casos de algunos Estados de la Europa Occidental de finales del siglo xIx y principios del xx. Tampoco puede circunscribirse del todo o reducirse a la definición de corte cultural de nación descrita y criticada por Gellner. Para Gamio, la nación era más un proyecto a construir y el culmen de una historia de división y fractura entre los indígenas y los grupos de origen europeo. Dicho proyecto requería de un amplio programa de convergencia social que abarcaba desde las mezclas de grupos sociodemográficos diferenciados ${ }^{22}$ hasta la instauración de una lengua franca y efectiva —el español—, pasando por la construcción de una cultura común - que tendría carácter nacional- $-\mathrm{y}$ un significativo proceso de equidad socioeconómica.

El proyecto de nación de Gamio fue un ejercicio de ingeniería social que si bien partía de una lectura de la historia de México y de un diagnóstico de los grupos étnicos a principios del siglo $\mathrm{xx}$, en su propuesta de convergencia social no retomó con suficiente claridad casi ningún elemento ni prácticas de la vida y tradiciones de los indígenas como eje fundamental en lo que se refiere a la fundación de la nueva

\footnotetext{
${ }^{22}$ Las ideas de Gamio sobre la "fusión de razas", "la convergencia social" y "forjar patria" (Gamio, [1916] 1992: 183) probablemente fueron antecedentes de la noción de "mestizaje" acuñada por Vasconcelos, entre otros, que marcaron los proyectos de construcción de la identidad nacional en el México posrevolucionario. La idea del "mestizo", que se asume como un "hecho natural" por ciertos sectores sociales y que nutre gran parte de los imaginarios sobre los mexicanos, fue y es una construcción social con diversos sentidos y símbolos, con una larga historia cuyos diversos orígenes pasan, entre otros autores, por las ideas de Gamio en Forjando patria (pro nacionalismo).
} 
cultura nacional por la que propugnaba. No obstante, una excepción considerable fueron sus ideas sobre el arte indígena y prehispánico (Gamio, [1916] 1992: 37-47). Tampoco hay una reflexión acabada sobre cómo, en el contexto de una desigualdad histórica-estructural y de relaciones de poder asimétricas, ocurriría el proceso de convergencia social entre los indígenas y el resto de la población, qué aportaría cada quién y cuál sería el papel que desempeñaría cada grupo. En el caso de los grupos étnicos, a pesar de que "podrían" conservar sus lenguas y algunas de sus actividades socioculturales, el proceso de convergencia social implicaba un cambio cultural significativo que iba desde la castellanización —el establecimiento del español como lengua francahasta la incorporación de prácticas occidentales de diversa índole: modelos educativos escolarizados, la medicina alópata, la ciencia, el uso de tecnología desarrollada en Europa y Estados Unidos, nuevos modelos de desarrollo productivo acordes con las modernas sociedades capitalistas, entre otros.

Las representaciones de los grupos étnicos y la propuesta integracionista de Forjando patria (pro nacionalismo) (Gamio, [1916] 1992: 183), junto a los planteamientos de investigación integral aplicados a la mejoría material de los indígenas en La población del Valle de Teotihuacán (Gamio, [1916] 1922: 10-11) y el resurgimiento del nacionalismo integracionista en Hacia un México nuevo (Gamio, 1987: 22-23) cuando fungía como asesor del proyecto educativo cardenista fueron antecedentes del quehacer y las políticas hacia los indígenas que este antropólogo llevó a cabo desde la dirección del III (1942-1960). El texto Consideraciones sobre el problema indígena (1948), compilación de editoriales de las revistas América Indígena y Boletín Indigenista del III, y recuento del programa de trabajo y actividades de Gamio al frente del Instituto, presenta, más allá de las diferencias propias de los periodos en que fueron escritas, fuertes líneas de continuidad con Forjando patria (pro nacionalismo) y Hacia un México nuevo respecto del papel de la antropología en la mejoría de los pueblos indígenas y al servicio del Estado, de la necesidad de formulación de un criterio étnico-cultural de los grupos étnicos, del concepto de cultura y las concepciones y valoraciones en relación con los indígenas y sus prácticas culturales - materiales e intelectuales-. La idea de "fusión de razas", estudiada con cierto detalle en Forjando patria (pro nacionalismo) y como parte nodal del proyecto integracionista de Gamio, tuvo sus antecedentes desde Clavijero y más tardíamente en Justo Sierra - con la ponderación del "cruzamiento" del indígena con el europeo en la Evolución política del pueblo mexicano (Sierra, 2009: 310-311) - y en Andrés Molina Enríquez, ${ }^{23}$ profesor de etnología y director del Museo Nacional (Olivé, 2000: 21), quien en Los grandes problemas nacionales (1909) sostenía que la integración étnica era una forma de equilibrar el cuerpo social de México (Molina, [1909] 1981: 305-322), siendo el mestizo en quien recaería la nacionalidad mexicana (Molina, [1909] 1981: 333-334; Basave, 2006: 64-66). Finalmente, el programa integracionista de Gamio en Forjando patria (pro nacionalismo), más que entenderlo sólo desde el lindero de su formación académica antropológica - de cierto corte particularista histórico boasiano-, puede ser leído en el contexto del proyecto social de Estado que se gestaba en el Constituyente de 1916 —que desembocó en la Constitución de 1917- durante el régimen carrancista y que buscaba unidad, cohesión social y homogeneidad.

\section{BIBLIOGRAFÍA}

Aguirre Beltrán, Gonzalo, 1976, Aguirre Beltrán: obra polémica, Instituto Nacional de Antropología e Historia, México.

\footnotetext{
${ }^{23}$ Olivé Negrete describe cómo la antropología formó parte de los influjos intelectuales que prepararon y nutrieron la Revolución. Particularmente apunta el caso de Molina Enríquez, tanto por su contribución por "hacer la patria mexicana" mediante la indagación de las cuestiones sociales en Los grandes problemas nacionales ([1909] 1981) como por su participación con Pastor Rouaix en el proyecto de reforma agraria que dio lugar al Artículo 27 de la Constitución de 1917 (Olivé, 2000: 21).
} 
1992, Teoría y práctica de la educación indígena, Universidad Veracruzana, Instituto Nacional Indigenista, Gobierno del Estado de Veracruz, Fondo de Cultura Económica, México.

Basave, Agustín, 2006, México mestizo. Análisis del nacionalismo mexicano en torno a la mestizofilia de Andrés Molina Enríquez, Fondo de Cultura Económica, México.

Boas, Franz, 1911, The Mind of Primitive Man, Macmillan, Nueva York.

, 1964, Cuestiones fundamentales de antropología cultural, Ediciones Solar, Buenos Aires.

Comas, Juan, 1975, "Manuel Gamio en la antropología mexicana”, en Anales de Antropología, vol. 12, pp. 47-65.

Díaz-Polanco, Héctor, 1990, Etnia, nación y política, Juan Pablos Editor, México.

Gamio, Manuel, 1922, La población del Valle de Teotihuacán, Talleres Gráficos de la Nación, México.

, 1942, "Franz Boas en México", en Boletín Bibliográfico de Antropología Americana, vol. 6, núms. 1-3, pp. 35-42.

_, [1948] 1966, Consideraciones sobre el problema indígena, Instituto Indigenista Interamericano, México.

—, 1972, Arqueología e indigenismo, Secretaría de Educación Pública, México.

— 1985, Antología, Coordinación de HumanidadesUniversidad Nacional Autónoma de México, México. les, Instituto Nacional Indigenista, México.

_, [1916] 1992, Forjando patria (pro nacionalismo), Porrúa, México.

Garciadiego, Javier, 2011, “La Revolución”, en Pablo Escalante (ed.), Nueva historia mínima de México, El Colegio de México, México.

y Kuntz Sandra, 2010, "La Revolución Mexicana", en Erick Velásquez y Erick Velázquez García (eds.), Nueva historia general de México, El Colegio de México, México.

Gellner, Ernest, 1994, Naciones y nacionalismos, Alianza, Madrid.

González Gamio, Ángeles, 1987, Manuel Gamio. Una lucha sin fin, Universidad Nacional Autónoma de México, México.

Harris, Marvin, 1979, El desarrollo de la teoría antropológica. Una historia de las teorías de la cultura, Siglo XXI Editores, México.

Hewitt de Alcántara, Cynthia, 1988, Imágenes del campo: la interpretación antropológica del México rural, El Colegio de México, México.

Hobsbawm, Eric, 2000, Naciones y nacionalismo desde 1780, Editorial Crítica, España.

Hutchinson, John y Anthony Smith (eds.), 1994, Nationalism, Oxford University Press, Oxford.

Instituto Nacional de Estadística, Geografía e Informática (INEGI), 1996, Estados Unidos Mexicanos. Cien años de censos de población, Instituto Nacional de Estadística, Geografía e Informática, México.

Kedourine, Elie, [1960] 1993, Nationalism, Blackwell, Cambridge.

Loyo, Engracia, 2011, "La educación del pueblo", en Dorothy Tanck de Estrada (coord.), Historia mínima. La educación en México, El Colegio de México, México, pp. 154-187.

Medina, Andrés, 1983, “Diez años decisivos”, en Andrés Medina y Carlos García (eds.), La quiebra política de la antropología social en México. Antología de una polémica. La impugnación, Universidad Nacional Autónoma de México, México, pp. 27-74.

Mendieta y Núñez, Lucio, 1979, Tres ensayos sociológicos. Augusto Comte, Emilio Durkheim, Manuel Gamio, Instituto de Investigaciones Sociales-Universidad Nacional Autónoma de México, México.

Molina Enríquez, Andrés, [1909] 1981, Los grandes problemas nacionales, Era, México.

Olivé Negrete, Julio, 2000, La antropología mexicana, Colegio Mexicano de Antropología, México.

Palerm, Ángel, 1976, "Introducción”, en Gonzalo Aguirre Beltrán, Aguirre Beltrán: obra polémica, Instituto Nacional de Antropología e Historia, México, pp. 7-20.

Schmidt, Henry, 1978, The Roots of Lo Mexicano. Self and Society in the Mexican Thought, 1900-1934, Texas A\&M University Press, Texas.

Sierra, Justo, 2009, Evolución política del pueblo mexicano, Porrúa, México.

Vasconcelos, José, 2010, La raza cósmica, Porrúa, México. Zúñiga Mejía, Raúl, 2011, "La escuela que surge de la Revolución”, en Fernando Solana, Raúl Cardiel Reyes y Raúl Bolaños Martínez (coords.), Historia de la educación pública en México (1876-1976), Fondo de Cultura Económica, México, pp. 183-233. 